\title{
A TALE OF TWO PROJECTS: WHY IT PROJECTS FAIL (AND WHY THEY SOMETIMES ACTUALLY SUCCEED)
}

\author{
David Wilton \\ Institute of Information and Mathematical Sciences \\ Massey University \\ Albany, New Zealand \\ Email: D.R.Wilton@massey.ac.nz
}

\begin{abstract}
This Case describes two similar outsourced IS projects that took place in Wellington, New Zealand (NZ) during the period 1992-99, with emphasis on the reasons why one project failed (the prime contractor repudiated the contract and the project was abandoned) and why the other succeeded. The same prime contractor was used for both projects and there were a number of other similarities, yet the outcomes were totally different. The Case provides lessons in some of the fundamental aspects of IS/IT project management, including scope, time, risk, human resources, procurement and quality management.
\end{abstract}

Keywords Information systems, project management

\section{INTRODUCTION}

This Case describes two similar outsourced IS projects that took place in Wellington, NZ during the period 1992-99, with emphasis on the reasons why one project failed while the other succeeded. When attempting to compare two projects, a difficulty frequently encountered is the potentially large number of variables. These include:

- Location (including physical/geographic differences, national and local political and legal environments).

- $\quad$ Size (\$ value) and scope of project.

- Type of organization (including mission and culture).

- Timeframe (in particular, technology available at that time).

- Acquisition strategy (outsourced or in-house; bespoke development or off-theshelf).

- $\quad$ Prime contractor (if outsourced).

In the Case, the organisations were very similar (both uniformed military or quasi-military federal government organisations), and the location, time period and prime contractor were identical. The budgets of the projects were of the same order of magnitude, and both were outsourced. This allows meaningful comparison of the projects, in terms of project management and acquisition strategies, particularly as one failed and the other was successful.

The two projects that are the subject of this Case are the NZ Defence Force (NZDF) Project FUSION $^{1}$ and the NZ Police Project INCIS $^{2}$. Schwalbe (2000) lists the following key project management functions: scope, time, quality, human resources (HR), cost, risk, communication, and procurement management. The two projects will be described using these factors as a framework.

\footnotetext{
${ }^{1}$ Not an acronym. The name was chosen to symbolise the integration of key management information systems.

${ }^{2}$ Integrated National Crime Information System
} 


\section{Learning Objectives}

The Case provides lessons in some of the fundamental aspects of IS/IT project management; including scope, time, risk, human resources, procurement and quality management. It also provides an opportunity for students to apply IS theory to the analysis and interpretation of a "real world" IT situation. Although the projects described in the Case were set in a national government IS context in a small southwest Pacific nation, the lessons are believed to be applicable to a global IS management context.

\section{Target Audience}

This Case has been used successfully with second year undergraduate students undertaking both Business and IS majors, and with postgraduate IS majors, to illustrate good and bad points of IS/IT project management. The similarities between the two projects, yet the totally different outcomes, provide telling lessons.

\section{PROJECT FUSION}

\section{Organisational Background - NZDF}

NZDF comprises some 9,000 regular force and 2,500 territorial force (part-time) Service men and women and 1,900 civilian staff across the armed services of Navy, Army and Air Force. Staff are located in many different parts of NZ with significant contingents serving in many different locations world-wide.

NZDF has an operational history extending from service in the South African War over 100 years ago to the present. Peace support operations have been a major element of operations undertaken in recent years. NZDF personnel are currently serving in 18 missions around the world, including Afghanistan and the Gulf of Oman in support of Operation Enduring Freedom, the global war against terrorism.

The corporate headquarters is located in the national capital, Wellington. Most major IT facilities (including servers for corporate applications) are also located in Wellington.

\section{Setting the Stage}

NZDF have historically used telecommunications services to maintain voice and messaging services to, and within, mobile elements, including ships at sea, aircraft in flight, and ground forces deployed into field locations. Since around 1980, mainframe computers have been used to store key corporate administrative data. The advent of the PC and affordable data communications networks in the 1980s facilitated the introduction of a distributed computing environment, allowing corporate data access from desktops in normal peacetime locations in NZ and by force elements deployed into the field or overseas.

Prior to 1988, the various IT elements of NZDF (telecommunications, administrative and operational computing) were regarded and managed as separate entities. At this stage, also, the emphasis was on in-house development of corporate IS applications. Following the merging of key IT functions and responsibilities in the late $1980 \mathrm{~s}$, various actions were undertaken to formulate enterprise-wide policies and standards. The next significant step in rationalising IT on an enterprise basis was an IS strategy study, conducted in 1991. Two of the key findings of this study were:

- Preference should be given to acquiring major IS applications "off-the-shelf" 
rather than by in-house development. (In-house development could be used, however, on a case-by-case basis, if proved to be beneficial by a sound business case.)

- The financial accounting system was at that stage outsourced to a bureau (in modern parlance, an Application Service Provider - ASP). Costs were calculated on a per-transaction basis and had been seriously underestimated. The excessively high cost of this arrangement meant that the system needed to be brought back inhouse as soon as possible ${ }^{3}$. Also, the linkages with the inventory management system needed to be improved. At that stage the in-house developed inventory management system had no financial visibility of assets once they were purchased and placed in inventory. This was contrary to the Mode B accrual accounting policy that the Government had introduced as part of the Financial Management Reform program in the late 1980s.

In early 1992, a small project team was formed and a project to rationalise the problems with the financial accounting and inventory management systems commenced.

Discussion Point 1: NZDF IS strategy expressed a preference for acquiring major applications "off-the-shelf" rather than by in-house development. What are the potential advantages and disadvantages of these two approaches?

\section{Brief Project History}

As outlined above, during 1991, NZDF completed an enterprise-wide IS Strategy Study. One of the key recommendations was that the (then) outsourced financial accounting system needed to be brought back in-house and that the linkages with the inventory management system needed to be improved. Project FUSION commenced in 1992; key objectives were:

- Replacing the existing:

$\bigcirc$ outsourced financial accounting system (due to excessive operating costs)

o inventory management system (due to no financial visibility of assets once purchased)

- with an integrated system.

- The new system was to have potential for integration of other corporate functions later (including HR, FM, engineering).

A brief chronology of the project is as follows:

- Registration of Interest (ROI) and Request for Proposals (RFP) were issued in 1992.

- $\quad$ IBM (NZ) was appointed prime contractor in late 1993. The system chosen was the Enterprise Resource Planning (ERP) integrated application SAP/R3.

- The finance system went live mid-1995.

- The inventory management system went live in 1997.

Discussion Point 2: the terms ROI, RFI, RFP and RFT tend to be used interchangeably with respect to procurement. What do they all mean and what is the difference between them?

The project required extensive upgrade of existing data communications network and deployment of new facilities to Defence establishments NZ-wide and many overseas locations. The project was on budget, slightly over time - of the order of 12 months. This was mainly due to the fact that the

\footnotetext{
${ }^{3}$ The possibility of another, cheaper, ASP arrangement was investigated; however, nothing was available at that time that provided the required functionality at a reasonable cost
} 
SAP/R3 inventory management system did not have a close fit with business requirements and significant business process engineering was required.

\section{Project Scope}

Project scope relates to defining and managing all the work involved in creating the deliverables required of the project and the processes used to create them. Project stakeholders need to come to an agreement early on as to the scope of the project; that is, what the project will actually encompass and the resultant deliverables. The most common encapsulation of the agreed scope is in the project charter, or plan, preparation and agreement of which should be an early step in the project.

In Project FUSION, while it was recognised in the strategic plan that the organisation should head towards an integrated ERP solution for its administrative IS, a decision was made to limit the deliverables from this project to financial accounting and inventory management modules. The main reason for this was that these two modules were the main business imperative, but there were also project implementation and management factors behind the decision.

\section{Procurement Management}

There are two possible approaches to acquiring or implementing a new information system: in-house development or by outsourcing (that is, contracting an external party to either develop or supply the required functionality "off-the-shelf"). Mixtures of these options (in-house/outsourced and developed/off-the-shelf) are also possible. If the outsourcing approach is chosen, in whole or in part, the project will then involve the significant processes of contractor selection, contract negotiation and ongoing contract management. In both the projects under review, a decision was made to outsource.

In Project FUSION, the desired procurement strategy was to obtain a system that was off-the-shelf as much as possible (i.e. minimal tailoring). An RFP was issued, evaluated and a preferred prime contractor selected. A contract was negotiated and signed, and successfully managed over the duration of the project. It is not possible to describe these processes in detail; however, a couple of noteworthy features were the decision to appoint a prime contractor, in a systems integration role, and the use of a skilled contract negotiator during the negotiations phase. While there were some differences between the parties during the project, all issues were subjected to discussion and the disputes procedure specified in the contract and all were resolved in an amicable fashion.

\section{Time}

Scope, time and cost are frequently cited as the key variables for judging the success (or otherwise) of a project. It is fairly obvious that stakeholders will require a project to be completed in a reasonable time frame, even if there are no critical deadlines resulting from legal, financial or external requirements. Modern computer-based project management tools usually provide an automated time scheduling capability, often coupled with resource management functionality. In both projects, the original scheduled timeframes were exceeded. In the case of FUSION, that was mainly because of the need to undergo business process re-engineering due to the fact that the offthe-shelf functionality of the inventory management system didn't completely fit the business requirements. This caused a delay of approximately 12 months, but that didn't create any major business problems. The use of automated scheduling software allowed close tracking of tasks, and the time slippage was predictable in advance and managed appropriately. 


\section{Quality}

Project FUSION established a quality assurance (QA) plan and a separate QA review team to oversee process quality, and to ensure that the prime contractor satisfactorily addressed product quality (as the system as off-the-shelf, this needed to be the prime contractor's responsibility). The QA review team reported to the business sponsors, which ensured its impartiality and independence from the project manager.

\section{HR}

The importance of recruiting and retaining suitable staff is well known. Phrases such as "people are our most important asset" have almost become clichés. Within a project, there are many different skill sets, individuals and groups required; from within the organisation, contractors and third parties such as legal and technical advisers.

Within Project FUSION, the recruitment and management of project staff is rated as adequate. As the system was largely off-the-shelf, development staff didn't pose significant issues. HR problem areas included:

- Initial difficulties in selecting a long-term NZDF Project Director, and the turnover (three individuals) during the duration of the project,

- Difficulties getting sufficient staff with appropriate business domain knowledge to undertake evaluation and testing,

- Turnover of prime contractor staff, including the key position of contractor PM.

Organisation culture aspects and attitudes to the project will be considered separately under Communication.

One aspect of project HR that perhaps deserves to be separated into a category of its own is that of project governance. This involves the organisational structure and processes established to undertake decision-making throughout the project. A large number of decisions will be required in any project: ranging from minor (normally required on a day-to-day basis) to major (usually on an infrequent basis).

In NZDF, the implementation of the overall IS strategy was the responsibility of a high-level IS steering group, which was charged with making recommendations on key issues (such as recommended prime contractor and major financial approvals) to the chief executive for approval. Within FUSION, there was a Project Executive Board, consisting of key stakeholders, responsible for oversight and other major decisions, and a Project Management Committee, chaired by the NZDF Project Director, responsible for routine, day-to-day decisions. (The QA review team, as noted previously, was separate from any of these groups.) There was a matrix of key decisions and documents for review, detailing who was required to comment and what the final approval level was.

\section{Cost}

Project cost is fairly obviously a major factor in any project, which implies the criticality of management of all resources, including financial (almost all other resources can be viewed as having a value expressible in monetary terms, and therefore should be regarded and managed with the same degree of importance as money). Although financial aspects of a project are important, they are not considered to be of critical issue in these Cases and will not be described in detail. The total cost of Project FUSION was of the order of NZ\$15M. This was within, or very close to, budget. 


\section{Risk}

Projects, by their very nature, invariably take place under conditions of uncertainty. This leads to a situation where identifying and countering risk is important.

Within Project FUSION, a risk assessment was carried out early in the project, and possible risks were identified. These were rated as relatively minor (and could therefore be managed) or could be mitigated with fairly modest counter-measures. The assessment was revalidated periodically throughout the project.

\section{Communication}

Communication is often considered to be the most critical factor impacting on the success, or otherwise, of a project, as it involves winning approval from all stakeholders, whether they be internal or external to the organisation, senior management or low-level system users. The broader process of gaining stakeholder approval and actually implementing the new system is usually termed change management. In these two Cases, the terms will be used synonymously, although change management is usually considered to encompass a wider scope.

Within Project FUSION, the need for a sound communications plan was identified early on in project planning. The main targets for communication were identified as senior management, who would make decisions, and the "users" of the new system, who would include not only data entrytype users, but also managers at most levels of the organisation who would use reports and ad hoc queries from the system. The communications plan was to inform senior management through the project governance arrangements (Project Executive Board, decision matrix, document review matrix) and to inform users by means of a regular project news bulletin, which became known as FUSENEWS. This was produced periodically (at least monthly, or more often if there was significant development to report), initially in hard copy form but later distributed optionally by email.

By the time the finance and inventory modules went live, all stakeholders were well informed, no significant cultural impediments were encountered and the implementations went relatively smoothly.

\section{Current Problems/Challenges Facing the Organisation}

The NZDF has gained widespread internal acceptance of the deliverables from Project FUSION. At least two more modules of the ERP package (facilities management and plant maintenance) have been implemented and consideration is being given to others, such as HR and payroll. Ongoing challenges include the implementation of higher-level Information Systems, such as decision support and executive support systems to assist decision-making by higher levels of management, and to integrate information provided from disparate (external and internal) sources and systems.

\section{PROJECT INCIS}

\section{Organisational Background - NZ Police}

NZ Police is the single nation-wide law enforcement agency responsible for enforcing criminal law in NZ. There is currently 8,800 staff (uniformed and civilian), operating from more than 400 community-based police stations throughout NZ.

Police provide services 24 hours a day, 365 days a year. Emergency response is a major component 
of Police operations, and Police respond to more than 1 million " 111 " calls each year. Police are also involved in crime prevention as well as responding to crime.

The corporate headquarters is located in the national capital, Wellington. Most major IT facilities (including servers for corporate applications) are also located in Wellington.

\section{Setting the Stage}

Like the NZDF, NZ Police have used IT extensively throughout their history; initially using telecommunications services to maintain voice communications with mobile elements, and more recently using corporate and desktop computing services to store and access administrative data. Operational data is now also stored on corporate servers and desktop computers. The advent of the PC and affordable data communications networks in the 1980s facilitated the introduction of a distributed computing environment, allowing access to corporate data from desktops and by mobile force elements.

The origins of the INCIS project go back to 1985. Considerable work was done to develop the INCIS vision and concept. The INCIS concept and vision was consistent and integrated with the Police five-year Strategic Plan published in 1993 which was developed around Community Oriented Policing (COP). Another factor in the gestation of the project was that, by the early 1990s, the thencurrent major database of criminal enforcement and court records, located in Wanganui (approximately $150 \mathrm{~km}$ from Wellington), was technologically obsolescent and in need of replacement.

In 1993, a business case was prepared that outlined the objectives of the project, and attempted to justify the cost on the basis that the new system would reduce paperwork, thereby freeing up more effort for front-line police work. It was estimated that the new system could save up to 540 staff, as the result reduced administrative tasks. This would ultimately result in savings for the taxpayer.

\section{Brief Project History}

In 1990 and 1992 NZ Police issued Requests for Information (RFI) that described the purpose of INCIS as:

... to support operational policing by providing improved information, investigation and analysis capabilities. This will contribute to the Police Mission Statement of minimising the incidence and effects of crime on the community through the detection and apprehension of offenders and by crime prevention strategies.

The proposed business functions to be performed by the system were: management of criminal information, case and investigation management, crime trend analysis, intelligence analysis, performance measurement, and special operations.

A brief chronology of the project is as follows:

- A Request for Tender (RFT) was issued in December 1992. By April 1993, tenders had been evaluated and a prime contractor recommended.

- The Business Case was presented to Cabinet ${ }^{4}$ in August 1993.

Discussion Point 3: what is the purpose of a business case and why would NZ Police have one at this stage?

- $\quad$ Significant revision of the Business Case in 1994.

- IBM (NZ) was appointed prime contactor in September 1994. The contract called

\footnotetext{
${ }^{4}$ Government executive body responsible for major funding decisions
} 
for bespoke development of applications to provide the required business

functionality.

- $\quad$ IBM repudiated the contract in August 1999.

- In late 1999, the project was cancelled. A State Services Commission Inquiry was held into failure. The subsequent report was widely publicized (Small, 2000).

\section{Project Scope}

The initial scope of INCIS was deliberately very broad, encompassing all aspects of operational policing. Small (2000 23) discusses the strategic objective as follows: "The overall strategic goal of 'reducing the incidence and effects of crime' transcends traditional crime prevention and seeks to stem and reverse crime trends", and goes on to note: "this is an ambitious goal and will not be achieved without significant changes in policies, processes and attitudes within the New Zealand Police."

Small (2000 27) reports that the scope changed significantly during the life of the project: "During its lifetime the Project underwent significant changes in emphasis. Its focus changed from Police strategy to financial objectives and then to a technology project".

Discussion Point 4: what is project scope creep and why is it regarded as a problem?

\section{Procurement Management}

Within Project INCIS, it was acknowledged that the scope of the project was so broad and the requirement so novel that an off-the-shelf system didn't exist at that time. A bespoke development contract was therefore sought. An RFP was issued and evaluated and a contract negotiated and signed (coincidentally, with the same prime contractor as for Project FUSION). Small (2000 190) notes many difficulties with the execution and management of this contract:

"In the initial stages of the Contract there was a partnering arrangement with Police. The Inquiry believes, whilst a partnering arrangement is acceptable in some circumstances, in this case the partnering arrangement was unlikely to work because the parties had different objectives, they were not ready to enter into contract, there were difficulties in relation to the fixed price nature of the Contract, and other factors."

After numerous disputes and much acrimony, the prime contractor eventually repudiated the contract, as previously noted.

\section{Time}

The project was approximately two years past deadline when it was cancelled.

\section{Quality}

There was no adequate QA regime within Project INCIS. Small (2000 161) states:

"The INCIS Project should have had comprehensive IQA [Independent QA] as part of a risk management process. In fact, the Project had no IQA. The failure to have comprehensive IQA was a material factor in significant risks not being identified and acted upon in the manner they should have been." 


\section{HR}

There were significant difficulties with HR in Project INCIS. According to Small (2000):

"Neither the Police nor IBM, at that time, had the resources, skills and experience needed to successfully deliver the INCIS application.” (p.163) ...

"The turnover of personnel within IBM was excessive and the location of work outside of New Zealand had significant risks.” (p. 190)

Organisation culture aspects and attitudes to the project will be considered separately under Communication.

In Project INCIS, the governance structure was initially fairly standard (see Small (2000) Chapter 6 Diagram 7). Small (2000) states: "The structure for governance and management of the INCIS Project shown in the Business Case was in accord with generally accepted practice." (p. 84). However, staffing turbulence and personal conflicts eroded the quality of project governance over time:

"The structure adopted by Police in 1995 departed from generally accepted practice in that ... the Project Director was reporting to the Director of I\&T [Information and Technical] and not to the Project Sponsor." (p. 85) ...

"The above ... factors led to a relationship of serious conflict between the Director of I\&T and the Project Director. ... The relationship issues were well known to Police governance. The Commissioner and the Sponsor spoke to the Director of I\&T and the Project Director about the relationship on a number of occasions but without any satisfactory result. The relationship issues had a negative effect on the INCIS Project team. The Police governance and management of the Project became to some degree dysfunctional." (pp. 99-100)

Discussion Point 5: if you were the project sponsor and you became aware of staffing conflicts as described above, what could (or should) you do about them? What are the implications for the project and the organisation as a whole? Discuss.

\section{Cost}

For Project INCIS, of the order of NZ\$130M was spent up until the time of cancellation. A significant portion of this was overspend, relative to an original budget of around NZ\$90M.

\section{Risk}

Within Project INCIS, the situation regarding risk is described by Small (2000):

"The INCIS Project was unique at the time. ... The Inquiry believes the fact that there were no existing packages that would meet the INCIS business specification should have been an early warning of the risks involved. The Project was made more complex and with a higher risk by the decision to develop the INCIS application. ... The Inquiry believes that, although the Project was of high risk, in 1993-94 the concept or vision of INCIS was sound ..." (p. 30)

"The Business Case for INCIS asked What are the key risks to manage? It then addressed risk management by stating that Police culture and work processes must continue to evolve; that Police were better prepared than ever before to undertake such a challenge; that the most critical element to success of the Project was to ensure that Police realised the benefits; and that a key part of realising benefits would be assumed by BPR. The right question was asked but the answer given was inadequate, vague and misdirected." (p. 119) 


\section{Communication}

Within Project INCIS, the business case stated a benefit of reducing the amount of time spent on administration by front-line police officers, thereby making more time available for operational duties and having the net effect of saving around 540 staff ( $6 \%$ of the workforce at that time). This claim became a political issue and was often hotly debated in the national parliament in relation to annual appropriations and expenditure by NZ Police, especially when the project began slipping. The project, particularly in relation to its time and budget overruns, was widely criticised in the news media and attracted national headlines such as Over-budget, Overdue and now simply Over (Broomhall, 1999) and Insights into INCIS Debacle (Gifford, 2002).

Internal INCIS communication was described by Small (2000 106) as follows:

"Police had a ... command-line culture - which, whilst suitable for line management of the Police, was not suitable for project management. ... INCIS was a business or commercial project rather than a policing operation. In the view of the Inquiry, a normal business and commercial culture, involving commitment, team-work, and open and frank reporting, would have been more successful than the application of line culture..."

As there were few actual deliverables from INCIS, it is difficult to assess how smoothly implementation may have been, and what stakeholder attitudes would have been at the time of implementation.

\section{Current Problems/Challenges Facing the Organisation}

In spite of the problems with the project, INCIS did deliver a number of benefits to NZ Police. The project delivered a technical infrastructure, including approximately 3,000 desktops, but this technical infrastructure was significantly modified from that specified in the original Contract. The project also delivered certain aspects of the INCIS application (Increment One) which was essentially a National Intelligence System (NIS) replacement. However, the project did not achieve its intended Business Case financial or business benefits (Small, 2000 57). A separate project had to be undertaken to carry out the necessary updates to the Wanganui computer and its applications.

There has been no similar (to INCIS) project attempted, and NZ Police still face the challenge of automating many operational policing functions. In time, at least some applications may possibly become available off-the-shelf.

\section{CASE QUESTIONS}

1. The UK Office of Government Commerce document Why IT Projects Fail (UK Office of Government Commerce, 2002) lists the following factors that may lead to project failure: design and definition failures, decision making failures, project discipline failures, supplier management failures, people failure.

The same document lists the following key questions that should be addressed relating to the project:

- Does the Department and other key stakeholders understand how this project will affect the business?

- Is the project properly staffed to enable effective leadership, decision-making and risk management to begin from day one and continue consistently to the end?

- How will the ways we work with our Supplier help this project to succeed?

Analyse and compare these two projects using the above framework. List and explain the key reasons why one succeeded and the other failed. What could Project INCIS management staff have done better, to ensure a higher probability of success? 
2. Within Project INCIS, the business case claimed a benefit of reducing the amount of time spent on administration by front-line police officers, thereby making more time available for operational duties and having the net effect of saving around 540 staff (some $6 \%$ of the thenworkforce). How realistic was this? Do IS projects normally allow large reduction of staff numbers (or save other resources such as finance)?

3. An aside: "Core" Technology Architecture.

The INCIS Project Technical Substitution Project Plan of 17 March 1995 defined the core architecture as:

"The components of the "core architecture" are deemed to be technologies which provide the basis for the design of the system technical architecture. That is to say that replacing any of the core architecture components will require the entire system design to be re-addressed. This will have an impact on cost and delivery schedules of INCIS. The core technologies are not subject to Technology Substitution. These core architecture components are:

- Host Operating System MVS,

- $\quad$ Station Server Operating System - OS/2 \& LAN Server;

- Desktop Operating System - OS/2 \& LAN Requestor;

- Host Database - DB2,

- $\quad$ Station Cabling - Token Ring; and

- Network Protocol - SNA.'

Comment on the above statement, particularly regarding the appropriateness of choosing these standards.

4. Describe what is meant by the term risk in relation to projects. How is risk quantified and how can it be mitigated? Describe and comment on the inherent levels of risk of the two projects and how well these were managed.

5. List and briefly discuss the reasons for, and possible advantages and disadvantages of outsourcing. What are the key considerations and requirements for managing a successful outsourcing relationship? How well were the relationships managed in the two projects outlined in this Case? How could things have been done better?

6. Communication is often considered to be the most critical factor impacting on the success, or otherwise, of a project, and involves winning approval from stakeholders. In general terms, what stakeholders may need to be targeted? What stakeholders were relevant in Projects INCIS and FUSION, and why the differences, if any? How successful was communication within the two projects? How well did the projects "fit" the cultures of the respective organisations?

7. Describe what is meant by the term quality in relation to projects. Describe and comment on the quality assurance regimes of the two projects and how well these were managed. Who is (or should be) responsible for quality assurance when a project is outsourced?

\section{REFERENCES}

Broomhall, K. (1999) Over-budget, Overdue and Now Simply Over, Christchurch Press, 11 August, Christchurch, NZ.

Gifford, A. (2002) Insights into the INCIS Debacle, NZ Herald, 11 June, Auckland, NZ.

Schwalbe, K. (2000) Information Technology Project Management, Thomson Learning, Cambridge MA.

Small, F. (2000) Ministerial Inquiry into INCIS, URL http://www.justice.govt.nz/pubs/reports/2000/incis_rpt/index.html, accessed 20 February 2001.

UK Office of Government Commerce (2002) Why IT Projects Fail, URL http://www.ogc.gov.uk, 
accessed 15 January 2004.

\section{APPENDIX 1: EXTRACT FROM PROJECT INCIS INQUIRY REPORT}

The key recommendations of the Inquiry were as follows (Small, 2000 Section 1.3):

1. The business case should reflect overall business strategy and should address technology resources and risks as well as financial issues.

2. Projects should normally use proven technology. Where it is necessary to use unproven technology, this should be reflected in an increased risk management process.

3. It is essential that a project be properly resourced in terms of skilled and experienced governance and management.

4. Strategic consideration should be given to the form and nature of the contract. There should usually be separate contracts for infrastructure and applications that should be in modules to give delivery of specific business benefits.

5. The appropriate form of contract should be signed only when the Government agency is satisfied that it has addressed and resolved all relevant issues including technology, resources and risks.

6. There must be comprehensive quality and risk management processes, including IQA ${ }^{5}$, in place.

7. The appointment of key personnel is critical and care needs to be taken in the appointment process to minimise the risk of conflict and, if possible, a top down appointment process is desirable. 8. Any conflict or dispute that adversely affects the project must be addressed promptly and in an effective way.

9. To maximise the prospects of success, a project needs to have tight and effective management.

10. The Government needs to define structure and role for approval and monitoring of large IT Projects.

11. The procedure for making application for approval of the Cabinet or Minister should be strengthened and made more rigorous to ensure that Cabinet and Ministers receive sound information and appreciate the risks of the project.

12. The approval by Cabinet or a Minister of a project should contain directions that ensure that the monitoring by the Monitoring agencies is as effective as practicable.

13. The approval and monitoring structures need to be resourced to enable them to effectively meet the expectations of Government.

(Note: 10-13 related to Government IT as a whole rather than specifically to NZ Police)

A statement that alluded to the key difficulties of the project is as follows:

"The implementation of the INCIS Project after the signing of the Contract was fraught with difficulties that arose from:

The fact that the parties had entered the Contract before they were ready.

The technology and architecture contracted for could not be delivered.

There were not sufficiently skilled and experienced personnel.

A dispute as to whether the Contract was sufficient for design of applications.

Business Process Re-engineering (BPR) not being commenced until after Contract ${ }^{6}$.

\footnotetext{
${ }^{5}$ Independent Quality Assurance

${ }^{6}$ This, presumably, would not have been a problem unless it was on the critical path, as it was also for NZDF Project FUSION
} 
Requirement for extensive changes.

Other factors." (Small, 2000 Section 6.9.1) 